\title{
Using magnetic susceptibility for predicting hydrocarbon contamination levels in a petroleum refinery compound in Isfahan Province, Iran
}

Shamsollah Ayoubi ${ }^{\mathrm{a}}{ }^{*}$, Mohammad Javad Samadi a, Hossein Khademi ${ }^{\text {a, }}$ Mehran Shirvani ${ }^{a}$, Yeboah Gyasi-Agyei ${ }^{b}$

a Department of Soil Science, College of Agriculture, Isfahan University of Technology, 84156-83111 Isfahan, Iran

b School of Engineering and Technology, Central Queensland University, Rockhampton, Australia

*Corresponding author: ayoubi@,cc.iut.ac.ir; Tel: +98-311-33913470; Fax:

+98-311-33913470

\begin{abstract}
Nowadays through the world as well as in Iran, petroleum hydrocarbons have majority contribution in environmental ricks for human and other organisms. Therefore, this study evaluates hydrocarbon pollution effects on soil chemical properties, as well as soil magnetic susceptibility on a petroleum refinery compound in Isfahan province, Iran. It also examines the efficacy of using magnetic signatures to predict hydrocarbon pollution of soils. Two sites (polluted and unpolluted) with similar intrinsic soil properties and environmental attributes were selected. A total of 120 soil samples were collected at two depths of $0-10$ and $10-30 \mathrm{~cm}$. Laboratory analysis included measurement of electrical conductivity $(\mathrm{EC}), \mathrm{pH}$, aqua regial extractable $\mathrm{Fe}\left(\mathrm{Fe}_{\mathrm{A}}\right)$, dithionite extractable $\mathrm{Fe}\left(\mathrm{Fe}_{\mathrm{d}}\right)$, magnetic susceptibility at low frequency $\left(\chi_{\mathrm{lf}}\right)$, total petroleum hydrocarbon (TPH), as well as powdery X-ray characterization. Polluted soils by petroleum hydrocarbons had significantly higher $\mathrm{EC}, \chi_{\mathrm{lf}}, \mathrm{Fe}_{\mathrm{A}}$ and $\mathrm{Fe}_{\mathrm{d}}$ and lower $\mathrm{pH}$ values compared to the unpolluted soils. Positive significance $(r=0.88, p$ b .01) was obtained between TPH and magnetic
\end{abstract}


susceptibility. Enhancement of magnetic susceptibility presumably attributed to formation of ferrimagnetic minerals such as magnetite because of degradation of hydrocarbon compounds. A multiple linear regression model was developed between magnetic susceptibility and TPH, and the results showed that the developed pedotransfer function could explain $86 \%$ of the variability of TPH in the studied area, and provided a reliable function to predict TPH in polluted soils, as a cost-effective and fast technique to be implemented in the polluted sites by petroleum hydrocarbons. It seems that inclusion of additional magnetic measures may improve the accuracy of the predictive model.

Keywords: Soil pollution, Pedotransfer function, Multiple linear regression, Oil refinery, Magnetic susceptibility

\section{Introduction}

Soil pollution is a growing threat to the health and quality of the human environment. This problem has been exacerbated due to the rapid growth of population and industry without considering natural resource constraints (Taghipour et al., 2011). Hydrocarbon pollution is one of the most common and dangerous pollutions caused by petroleum industries such as refineries, and oil pipelines and tanks leak causing environmental pollution (Marian et al., 2011). The negative impacts of oil pollutants, especially polycyclic aromatic hydrocarbons (PAHs), on soil productivity and plant growth have already been investigated by various researchers (Wild et al., 1991; Kayode et al., 2009). PAHs, as major components 
of soil, have partially led to a higher level of lung cancer risk, particularly in developing countries (Xia et al., 2013; Liang et al., 2019). Furthermore, these pollutants may cause major threats to ground water resources through leaching the soils (Rijal et al., 2010). Rapid assessment and selection of proper remediation strategies require new

approaches and technologies for exploring and monitoring hydrocarbon pollution in sediments and soils. Magnetic methods as a quick and nondestructive approach have been efficiently applied for detecting anthropogenic pollution in power plants (Heller et al., 1998; Kapicka et al., 2000; Ayoubi et al., 2018a; Ayoubi et al., 2018b); metallurgical dusts (Naimi and Ayoubi, 2013; Naderizadeh et al., 2016), urban airborne particulates (Dankoub et al., 2012) and road traffic (Gautam et al., 2005).

Although magnetic measures are widely being used for various pollutants in soils and sediments, few studies have been done to monitor the pollution of soils and sediments by hydrocarbon pollutants. Hanesch and Scholger (2002) found a significant relationship between polycyclic aromatic hydrocarbon (PAH) content and soil magnetic susceptibility near the Donawitz steel mill in Austria. Halsall et al. (2008) showed that the combined PAHs and magnetic analysis could provide a precise means of identifying outdoor trafficderived pollution, and could also discriminate between different types of indoor pollution.

Studies in Western Lake Ontario in Canada (Morris et al., 1995), the Gulf of Santos in Mexico (Martins et al., 2007), the Bay of Bengal in India (Venkatachalapathy et al., 2011), and the Austrian tundra (Hanesch and Scholger, 2002) showed that magnetic susceptibility could be a reliable 
and cost-effective approach for defining the extent of sediment pollution by PAHs. Rijal et al. (2010) concluded that changes in the magnetic properties could determine the fluctuations in the subterranean water surface of hydrocarbon contaminated areas. There was also a connection between the formation of new magnetite and the some characteristics of sediments such as total iron, $\mathrm{pH}$ and organic carbon. Rijal et al. (2011) established a positive and very strong relationship between magnetic susceptibility and oil hydrocarbons. They reported a correlation of 0.85 between total hydrocarbons and magnetic susceptibility, but they found a weak correlation between magnetic susceptibility and aromatic multi-rigorous hydrocarbons in hydrocarbon-contaminated soils and sediments at the former oil field Hänigsen, Germany. Some researchers have even successfully employed the variability in magnetic susceptibility for the exploration of oil reserves (Liu et al., 2006; Aldana et al., 2003 and Aldana et al., 2011).

The oil industry is the main backbone of the Iranian economy, and subsequently petroleum refineries have been expanded throughout the country. Because of some accidental events and improper management, some soils around refineries have been polluted by petroleum hydrocarbons. This study is the first attempt in Iran conducted to:

i) explore the influences of petroleum hydrocarbons on some dynamic properties (soil $\mathrm{pH}, \mathrm{EC}$, some forms of $\mathrm{Fe}$ ) and magnetic measures and reasons of magnetic susceptibility enhancement following pollution, and ii) evaluate the efficacy of magnetic susceptibility measures to estimate the content of total petroleum hydrocarbons (TPHs) in some polluted soils at the Isfahan petroleum refinery, central Iran. 


\section{Materials and Methods}

\subsection{Study sites and sampling}

The study area, near the Isfahan petroleum refinery, is located $30 \mathrm{~km}$ north of Isfahan city $\left(51^{\circ} 32^{\prime} \mathrm{E}\right.$ longitude, $32^{\circ} 46^{\prime} \mathrm{N}$ latitude), central Iran (Fig. 1). Based on the recorded documents and visual observations in the field, two adjacent sites including an unpolluted site and a petroleum polluted one were selected near the refinery (Fig. 1). At the Isfahan province, an oil refinery complex was established in 1979 and now has a vital contribution in refining of crude oil. According to our observations because of recent leakage of crude oil in surface soil only 30 upper horizons were affected and 0-30 was considered for evaluation our hypothesis. An illustration of surficial pollution of studies soils is given in Fig. 2. As it is seen in figure, surficial leakage and existence of an impermeable layer at $30-50 \mathrm{~cm}$ inhibited leaching of crude oil to subsurface horizons. Hence, surface layers including two depths of 0-10 and 10-30 cm were investigated. These sites share similarity in intrinsic soil properties and environmental attributes. Similar variations in clay, silt and sand in two sites confirmed this hypothesis. Forty locations in the polluted site and 20 in the unpolluted one were randomly selected with distances varied from 200 to $400 \mathrm{~m}$ apart away (Fig. 1). For each location, soil samples were collected from two depths (0-10 and $10-30 \mathrm{~cm})$, thus obtaining a total of 120 soil samples. Soil samples were airdried and sieved through a $2 \mathrm{~mm}$ sieve before laboratory analyses. Soils at the studied sites classified dominantly as Typic Torriorthents and Typic Calcigypsids in some areas according to Soil Survey Staff (2014). 


\subsection{Laboratory analyses}

The magnetic susceptibility of the soil samples was measured by a MS2 Meter (Bartington Instruments Dual Frequency) at low frequency ( $\left.\chi_{\mathrm{lf}}\right)$. Selected chemical properties were determined for the soil samples. The soil electrical conductivity (EC) and $\mathrm{pH}$ were measured in a 1:2.5 soil to water ratio suspension. The percentage of calcium carbonate equivalent (CCE) was determined by the calcimetric method (Burt, 2004). Particle size distribution was measured using the sieving and pipette methods (Gee and Bauder, 1986).

The dithionite-citrate bicarbonate (DCB) approach was used to determine $\mathrm{Fe}_{\mathrm{d}}$ (Sheldrick, 1984). Aqua regial extractable $\mathrm{Fe}\left(\mathrm{Fe}_{\mathrm{A}}\right)$ was extracted by digestion of soil samples with aqua regia (Rodriguez Martin et al., 2006). This method results in concentrations normally referred to as pseudo-total, as the method does not completely destroy the silicates (Facchinelli et al., 2001). Following the extraction of $\mathrm{Fe}_{\mathrm{A}}$, and $\mathrm{Fe}_{\mathrm{d}}$, the concentrations of different forms were determined by Atomic Absorption Spectrometry (AAS). The accuracy of the procedure was determined by analyzing the certified reference material San Joaquin \#2709 (National Institute of Standards and Technology, USA). The detection limit of ASS for Fe was $0.1 \mathrm{mgL}^{-1}$ and the precision ( $n$ $=3$ ) obtained was below $5 \%$.

Regulatory bodies have introduced total petroleum hydrocarbon (TPH) concentrations as an indicator for the level of soil pollution by petroleum products. In this study, TPH content in all collected samples was measured by the Soxhlet extraction method EPA 3450. Soxhlet extraction is regarded as an efficient technique commonly used in extracting semivolatile organic compounds from soil (Good et al., 1995; Buddhadasa et al., 2001). 
Crushed soil samples were examined with a Bruker AXS D8 ADVANCE X-ray diffractometer (XRD) using $\mathrm{Cu} \mathrm{K}$-alpha radiation, a step size of $0.02^{\circ}$ and a time per step of $1 \mathrm{~s}$. X-ray scanning ranged from $10^{\circ}$ to $80^{\circ}$ 2-theta. Relative peak positions and intensities were identified as the basis for semi-quantitative estimates of ferrimagnetic minerals (magnetite and maghemite) percent (Soil Survey Staff, 2014).

\subsection{Statistical analysis}

Classical descriptive statistics were computed using SPSS 16.0 (Swan and Sandilands, 1995). Likewise, the correlation coefficients between magnetic susceptibility ( $\left.\chi_{\mathrm{lf}}\right)$ and the different variables ( $\mathrm{Fe}_{\mathrm{d}} ; \mathrm{Fe}_{\mathrm{A}}, \mathrm{EC}, \mathrm{pH}$ and $\mathrm{TPH}$ ) were calculated using SPSS 16.0 (Swan and Sandilands, 1995). Multiple-linear regression (MLR) in SPSS Ver. 16 was employed to predict the concentrations of TPH using the magnetic measurements and soil chemical properties. MLR modeling was done using the initial variables (x) and transformed variables $\left[\mathrm{x}^{-1}, \mathrm{x}^{2}, \log (\mathrm{x}), \ln (\mathrm{x})\right.$, exp. $(\mathrm{x})$ and $\left.\mathrm{x}^{0.5}\right]$ as predictors. The factors included in the qualified model were selected based on probability $\leq .05$ following Freund and Littell (2000). Also, a paired Student's $t$-test ( $P$ b .05)

was applied to compare the variables between the polluted and the unpolluted soils. 


\section{Results ad Discussion}

\subsection{Descriptive analysis}

The descriptive statistics of the studied variables in two sites (polluted and unpolluted) at two depths of $0-10$ and $10-30 \mathrm{~cm}$ are given in Tables 1 and 2 . According to the results of Table 1 , almost all variables were normally distributed except for EC in two depths of the unpolluted site based upon the skewness values that ranged from -1 to +1 . The magnetic susceptibility varied from 20.23 to $76.3 \times 10^{-8} \mathrm{~m}^{3}$ $\mathrm{kg}^{-1}$ with a mean of 42.9 and $32.9 \times 10^{-8} \mathrm{~m}^{3} \mathrm{~kg}^{-1}$ in the $0-10$ and $10-30 \mathrm{~cm}$ soil layers, respectively. The mean value of $\chi_{\text {lf }}$ is very similar to those of the natural soils of Isfahan province $\left(40 \times 10^{-8} \mathrm{~m}^{3} \mathrm{~kg}^{-1}\right)$ as reported by Ayoubi et al. (2002). Low mean values of 0.21 and $0.17 \mathrm{~kg} \mathrm{~kg}^{-1}$ in the $0-10$ and $10-30 \mathrm{~cm}$ soil layers, respectively, were observed for the TPH. The highest coefficient of variation (CV) was observed for EC and $\mathrm{TPH}$, and the lowest variability was observed for $\mathrm{pH}(\mathrm{CV} \sim 4 \%)$ for this site. High variability in $\mathrm{EC}$ and low variability in $\mathrm{pH}$ is consistent with the findings of Karimi et al. (2011) and Dankoub et al. (2012) in similar soils of Isfahan. Based upon the CCE values (45-50\%), the studied soils can be classified as calcareous and carbonate enriched soils.

The descriptive statistics of the variables in the polluted site are given in Table 2 . Like the unpolluted site, the highest variability was observed for EC and TPH. Also, $\chi_{\mid f}$ showed a high variability with mean CV of $94 \%$ and $92 \%$ for the $0-10$ and $10-30 \mathrm{~cm}$ soil layers, respectively. Lowest variability was observed for $\mathrm{pH}$, similar to the unpolluted site. Valaee et al. (2016), Paz Gonzalez et al. (2002) and Lopez Granados et al. (2002) 
also obtained the lowest coefficient of variation for $\mathrm{pH}$. The mean TPH content varied from 0.10 to $35.8 \mathrm{~kg} \mathrm{~kg}^{-1}$ in the $0-10 \mathrm{~cm}$ layer, and 3.1 to $31.2 \mathrm{~kg} \mathrm{~kg}^{-1}$ in the 10 $30 \mathrm{~cm}$ layer. For the magnetic susceptibility at low frequency, mean values of 195.4 and $202.4 \times 10^{-8} \mathrm{~m}^{3} \mathrm{~kg}^{-1}$ for the $0-10$ and $10-30 \mathrm{~cm}$ soil layers, respectively, were recorded. However, the $\chi_{\text {If }}$ of the polluted soils are much higher than the values of the natural soils of Isfahan (Ayoubi et al., 2002), and even higher than the polluted soils caused by urbanization in Isfahan city $\left(\chi_{\mathrm{If}}=74.34 \times 10^{-8}\right.$ $\mathrm{m}^{3} \mathrm{~kg}^{-1}$, Karimi et al., 2011; $\chi_{\mathrm{lf}}=80.20 \times 10^{-8} \mathrm{~m}^{3} \mathrm{~kg}^{-1}$, Dankoub et al., 2012) and industrialization $\left(\chi_{\mathrm{lf}}=107.5 \times 10^{-8} \mathrm{~m}^{3} \mathrm{~kg}^{-1}\right.$, Naimi and Ayoubi, 2013). The higher value of magnetic susceptibility at this site is mainly attributed to changes induced by hydrocarbon pollution which is discussed in the next section.

\subsection{Variability of soil properties induced by TPH pollution}

The results of the analysis of variance (ANOVA, results not shown here) indicated that there was a significant $(P \mathrm{~b} .05)$ difference among almost all the studied variables in both sites. Fig. 3 compares the means of the variables for the polluted and unpolluted sites, and for the two soil sampling depths. As observed in Fig. 3A, the polluted soils show higher values of EC for both depths compared to unpolluted soils. It seems that increase of salinity following oil pollution leads to release of elements to soil solution (Balanchandran et al., 2012). Moreover, measurements of crude oil in the Isfahan refinery showed that it had salt levels of EC of $0.4 \mathrm{dS} / \mathrm{m}$ and its pollution of the soils have enhanced soil salinity. The results of the chemical analysis also show that $\mathrm{pH}$ levels are higher in the polluted soils compared with the unpolluted soils (Fig. 3B). Although in carbonatic soils such as the study 
area soils, carbonate has significant contribution in regulating the soil $\mathrm{pH}$ (Lindsay, 1979), but inclusion of TPH has reduced the $\mathrm{pH}$ significantly, probably because of the addition of petroleum with high concentration of $-\mathrm{OH}$ and $-\mathrm{COOH}$ bonds in the hydrocarbon compounds leads to lowering of $\mathrm{pH}$ values. These results are in accordance with the findings of Tang et al. (2012) who reported that inclusion of petroleum hydrocarbons to soils led to lower $\mathrm{pH}$. The lowering of $\mathrm{pH}$ may be attributed to activities of specific bacteria that are involved in TPH degradation that generate weak acids (Das and Chandran, 2011; Tang et al., 2012). Moreover, crude oil has some acidic compounds such as Naphthenic acid, Stearic acid, and Valeric acid that may lead to lowering soil $\mathrm{pH}$ after inclusion to soil.

In addition, the results of ANOVA (results not shown) showed significant differences ( $p \mathrm{~b}$ $.05)$ for the studied forms of iron, including aqua regial extractable $\mathrm{Fe}\left(\mathrm{Fe}_{\mathrm{A}}\right)$ and $\mathrm{DCB}$ extractable iron $\left(\mathrm{Fe}_{\mathrm{d}}\right)$ between contaminated and non-contaminated soils (Fig. 3). In general, all studied forms of Fe showed higher values in soils polluted by petroleum hydrocarbons, confirming that these pollutants contain meaningful values of metals such as Fe. Analytical results of crude oil by atomic absorption spectroscopy (ASS) revealed that total $\mathrm{Fe}$ was $42 \mathrm{mg} \mathrm{Kg}^{-1}$ and the enhancement of $\mathrm{Fe}$ in polluted soils mainly attribute to Fe that released to soil following pollution. Brown (1983), using ICP analysis, showed that $\mathrm{Fe}$ content in petroleum varied from 27 to $35 \mu \mathrm{g} / \mathrm{g}$. Many studies have reported that the soils near the petroleum refinery stations have been heavily polluted by heavy metals in addition to hydrocarbons (Atagana, 2011; Dong et al., 2013). Also, other researchers (Mariana et al., 2011; Uquetan et al., 2017) have confirmed that one of the most important influences of crude oil pollution is the addition of heavy metals such as Fe, $\mathrm{Mn}$ and $\mathrm{Pb}$ to the soils. 


\subsection{Variability of magnetic susceptibility and its association with TPH}

According to the results of the mean comparisons, there are significant differences $(\mathrm{p} \mathrm{b}$ $.05)$ between the polluted and unpolluted sites for magnetic susceptibility at low frequency. The mean magnetic susceptibility in the polluted site samples were much higher than those of the unpolluted site for both sampling layers, about 4.6 times higher in the $0-10 \mathrm{~cm}$ layer, and 6.3 times higher in the $10-30 \mathrm{~cm}$ soil layer. Many researchers have confirmed the pollution of soils by hydrocarbon enhanced magnetic susceptibility (Baedecker et al., 1993; Porsch et al., 2014). Some mechanisms in the presence of hydrocarbons have been proposed for enhancement of magnetic susceptibility. Porsch et al. (2014), in a controlled experiment through incubation of six soils by gasoline hydrocarbon and microcosms, showed that magnetic susceptibility increased in four out of the six soils because of degradation of hydrocarbon to Fe(III) leading to formation of ferromagnetic minerals such as magnetite. Following stabilization of magnetic susceptibility during the experiment, organic matter and ferrihydrite were added up to the samples to prove that bioavailability of iron had more contribution to enhancement of magnetic susceptibility. Measurement of magnetic susceptibility showing diamagnetic behavior of crude oil with magnetic susceptibility lower that zero $\left(-1 \times 10^{-8} \mathrm{~m}^{3} \mathrm{~kg}^{-1}\right)$. Therefore any changes in magnetic susceptibility of soils following oil pollution is attributed to processes that occurred in transformations of iron forms in soil.

Ferromagnetic minerals are well known phases formed in crude oil during oil biodegradation (McCabe et al., 1987) and further decomposition following inclusion of microorganisms to the soil (Lovley et al., 1989; Hamamura et al., 2006; Borch et al., 2010). Some $\mathrm{Fe}^{3+}$-reducing microorganisms can use hydrocarbons as carbon sources and 
reduce $\mathrm{Fe}^{3+}$ to $\mathrm{Fe}^{2+}$ (Lovley and Anderson, 2000; Lovley et al., 1989). Both $\mathrm{Fe}^{3+}$ microbial regeneration and $\mathrm{Fe}^{2+}$ oxidation can lead to magnetite formation (Lovely et al. 1989). Fe(III) reducers could reduce poorly crystallized ferrihydrite as well as higher crystalline $\mathrm{Fe}$ (III) minerals such as magnetite, hematite and goethite (Konhauser et al., 2011). Other studies have shown that hydrocarbon contaminants in soils and sediments also affect $\mathrm{Fe}^{3+}$ reducing agents and $\mathrm{Fe}^{2+}$ oxidants. In turn, $\mathrm{Fe}$ (II) could be oxidized by aerobic and anaerobic Fe (II) oxidizing microbes which can also drive magnetite formation (Kappler and Straub, 2005; Konhauser et al., 2011; Dippon et al., 2012). These processes can lead to changes in the variability of magnetic minerals and consequently affect the magnetic susceptibility.

Positive and significant correlation among studied forms of Fe (Aqua regial extractable Fe, extractable with DCB and extractable with oxalates) with magnetic susceptibility (Fig. 4) confirmed the prominence of variability of iron forms on magnetic susceptibility that is regulated by hydrocarbon degradation in the studied soils. Fig. 5 shows XRD patterns of representative samples of the polluted and the unpolluted soils. According to the XRD patterns, Fe-oxides minerals, magnetite/ maghemite (d-spaces of $0.1488,0.252$, and 0.296 $\mathrm{nm})$, hematite (d-space of $0.368 \mathrm{~nm})$ and goethite (d-space of $0.418 \mathrm{~nm}$ ) were identified in both samples, but magnetite/maghemite as the ferromagnetic phase was significantly higher in the polluted soils (Fig. 5).

The results of the correlation analysis (Table 3) show that magnetic susceptibility displays negative relationships with electrical conductivity ( $p$ b .01, $r=-0.33$ ) and calcium carbonate equivalent ( $p$ b .05, $\quad r=-0.19$ ). Other researchers have confirmed that, in arid soils including gypsum, carbonates and soluble slats, may lead to reduction of magnetic susceptibility because of the diamagnetic behaviours of these minerals (Marwick, 2005; 
Naimi and Ayoubi, 2013).

Also, the results of correlation analysis indicated that there was a significant $(r=0.883, \mathrm{p} \mathrm{b}$ .01 ) and positive linear relationship between magnetic susceptibility and TPH content (Fig. 4). As already discussed, magnetite/maghemite formation following hydrocarbon degradation may be the major process for enhancing magnetic susceptibility. Hence, higher content of TPH has led to higher content of ferrimagnetic minerals and, consequently, to higher values of magnetic susceptibility. Similarly, Venkatachalapathy et al. (2011) in their study in sediment cores from the north east coast of Tamilnadu, Bay of Bengal, India, found positive and significant $(r=0.86, \mathrm{p} \mathrm{b} .01)$ relationships between petroleum hydrocarbons and magnetic susceptibility. Rijal et al. (2011), in a study of the relationship between magnetic susceptibility and hydrocarbon pollution in soils and sediments at the former oil field at Hänigsen, Germany, showed that there was a positive and significant relationship $(r=$ 0.85) between magnetic susceptibility and TPH. Moreover, Martins et al. (2007) studying sediment cores from the Santos Estuary, Brazil, and Meliana (2017) in Wonocolo oil field, Indonesia, showed a high potential of magnetic susceptibility for exploration of hydrocarbon pollutions in soils and sediments.

For development of a pedotransfer function for TPH, stepwise multiple regression was applied using magnetic susceptibility $\left(\chi_{\mathrm{lf}}\right)$ as predictor. Also, untransformed variables (x) and transformed variables $\left[\log (\mathrm{x}), \operatorname{Ln}(\mathrm{x}), \mathrm{x}^{2}, \mathrm{x}^{-1}, \mathrm{x}^{0.5}\right.$ and exp.(x)] were used as predictors in the analysis. The developed model with the highest coefficient of determination $\left(\mathrm{R}^{2}\right)$ and lowest root mean square error (RMSE) was identified as follow:

$\%$ TPH $=6.516-144.67 \times\left(\frac{1}{\chi_{l f}}\right)+2.31 \times 10^{-5} \times\left(\chi_{l f}\right)^{2} ; \quad \mathrm{R}^{2}=0.86, \mathrm{RMSE}=0.02 \%$ 
Eq. (2) shows that $1 / \chi_{1 f}$ and $\chi_{1 f}^{2}$ were the best predictors explaining about $86 \%$ of the variability of TPH in the studied area. It is plausible to use this model to reliably predict TPH with easily measured magnetic properties as compared to expensive and time consuming chemical protocols. It is concluded that magnetic measurements are a suitable, cheap and rapid method for detailed study of petroleum hydrocarbon pollution in the polluted soils around the refinery petroleum compounds.

\section{Conclusion}

The motivation for the present investigation was the hypothesis that soil magnetic susceptibility measurements could be a cost-effective and a quick process for assessing localized hydrocarbon pollution in the field. Petroleum hydrocarbon contaminants have significantly changed the soil properties. The electrical conductivity and total Fe content were increased and $\mathrm{pH}$ was lowered in the polluted soils compared to unpolluted ones. Magnetic susceptibility at low and high frequencies were enhanced significantly in the polluted soils by hydrocarbons mainly due to the bio-degradation of hydrocarbons that induced formation of ferrimagnetic minerals such as magnetic or maghemite. The results of XRD analysis confirmed the higher presence of these minerals in the polluted soils. High positive and significant relationship between magnetic susceptibility and TPH confirmed enhancement of magnetic susceptibility with increasing hydrocarbons in the soils. The developed MLR model revealed that magnetic measures could be used as a costeffective, fast and efficient way for evaluating soil pollution by hydrocarbons in petroleum refinery compounds. It is speculated that inclusion of complementary magnetic 
measures such as natural remanent magnetization and natural isothermal remanent magnetization to the MLR model might improve the efficacy of this technique.

\section{Acknowledgements}

The authors would like to thank Isfahan University of Technology for the financial support of this study.

\section{References}

Hanesch, M., Scholger, R., 2002. Mapping of heavy metal loadings in soils by means of magnetic susceptibility measurements. Environ. Geol. 42, 857-870.

Aldana, M., Costanzo-Alvarez, V., Diaz, M., 2003. Magnetic and mineralogical studies to characterize oil reservoirs in Venezuela. Lead. Edge 22, 526-529.

Aldana, M., Costanzo-Alvarez, V., Gomez, L., Gonzalez, C., Rada, M., 2011. Identification of magnetic minerals related to hydrocarbon authigenesis in Venezuelan oil field using an alternative decomposition of isothermal remanence curves. Stud. Geophys. Geod. 55, 343-358.

Atagana, H., 2011. Bioremediation of co-contamination of crude oil and heavy metals in soil by phytoremediation using chromolaena odorata (L) king \& H.E. Robinson. Water, Air and Soil Polution. 215, 261-271.

Ayoubi, S., Jalalian, A., Karimian Eghbal, M., 2002. In: Angel, Faz, Ortiz, R., Mermut, A.R. (Eds.), Role of pedogenesis in distribution of magnetic susceptibility in two Aridisols from Isfahan, Central Iran. International Conference of SUMASS, Spain, pp. 49-50. 
Ayoubi, S., Jababri, M., Khademi, H., 2018a. Multiple linear modeling between soil properties, magnetic susceptibility and heavy metals in various landuses. Modeling Earth Systems and Environment. 4, 579-589.

Ayoubi, S., Soltani, Z., Khademi, H., 2018b. Particle size distribution of Heavy Metals and magnetic Susceptibility in an Industrial Site. Bull. Environ. Contam. Toxicol. 100, $708-714$.

Baedecker, M.J., Cozzarelli, I.M., Eganhouse, R., Siegel, D.L., Bennett, P., 1993. Crudeoil in a shallow sand gravel aquifer. III. Biogeochemical reactions and mass balance modeling in anoxic groundwater. Appl. Geochem. 8, 569-586.

Balanchandran, C., Duraipandiyan, V., Balakrishna, K., Ignacimuth, S., 2012. Petroleum and polycyclic aromatic hydrocarbons (PAHs) degradation and naphthalene metabolism in Streptomyces sp. (ERI-CPDA-1) isolated from oil contaminated soil. Bioresour. Technol. 112, 83-90.

Borch, T., Kretzschmar, R., Kappler, A., Cappellen, P.V., Ginder-Vogel, M., Voegelin, A., Campbell, K., 2010. Biogeochemical redox processes and their impact on contaminant dynamics. Environ. Sci. Technol. 44, 15-23.

Brown, R.J., 1983. Determination of trace metals in petroleum and petroleum products using an inductively coupled plasma optical emission spectrometer. Spectrochim. Acta B At. Spectrosc. 38 (1-2), 283-289.

Buddhadasa, S.A., Barone, S., Bigger, S.W., Orbell, J.D., 2001. Extraction of Hydrocarbons from Clay Soils by Sonication and Soxhlet Techniques. Sekiyu Gakkaishi 44 (6), 378-383.

Burt, R., 2004. Soil Survey Laboratory Methods Manual. USDA-Natural Resources Conservation Service, Lincoln. 
Dankoub, Z., Ayoubi, S., Khademi, H., Sheng Gao, Lu, 2012. Spatial distribution of magnetic Properties and selected Heavy Metals as Affected by Land Use in Calcareous Soils of the Isfahan Region. Central Iran. Pedosphere 22, 33-47.

Das, N., Chandran, P., 2011. Microbial Degradation of Petroleum Hydrocarbon Contaminants: an Overview. Biotechnology Research International 2011 (Article ID 941810.13 pages).

Dippon, U., Pantke, C., Porsch, K., Larese-Casanova, P., Kappler, A., 2012. Potential function of added minerals as nucleation sites and effect of humic substances on mineral for-mation by the nitrate-reducing Fe(II)-oxidizer Acidovorax sp BoFeN1. Environ. Sci. Technol. 46, 6556-6565.

Dong, Z., Huang, W.H., Xing, D.F., Zhang, H.F., 2013. Remediation of soil cocontaminated with petroleum and heavy metals by the integration of electrokinetics and biostimu- lation. J Hazardous Materials. 260, 399-408.

Facchinelli, A., Sacchi, E., Mallen, L., 2001. Multivariate statistical and GIS-based approach to identify heavy metal sources in soils. Environ. Pollut. 114, 313-324.

Freund, R.J., Littell, R.C., 2000. SAS System for Regression. SAS Inst, Cary (NC).

Gautam, P., Blaha, U., Appel, E., 2005. Magnetic susceptibility of dust-loaded leaves. Atmos. Environ. 39, 2201-2221.

Gee, G.W., Bauder, J.W., 1986. Particle size analysis. In: Klute, A. (Ed.), Methods of Soil Analysis: Part 1. Physical and Mineralogical Methods. Agronomy Handbook no 9. ASA/SSSA, Madison, WI, pp. 383-411.

Good, J., Magor, B., Seignior, M., 1995. A review of procedures used to measure total petroleum hydrocarbons for contaminated site assessment. Combined 13th 
Australian Symposium on Analytical Chemistry, Royal Australian Chemical Institute, Darwin, Australia, 9-14 July.

Halsall, C.J., Maher, B.A., Karloukovski, V.V., Shah, P., Watkins, S.J., 2008. A novel approach to investigating indoor/outdoor pollution links: combined magnetic and PAH measurements. Atmospheric Environment 42, 8902-8909.

Hamamura, N., Olson, S.H., Ward, D.M., Inskeep, W.P., 2006. Microbial population dynamics associated with crude-oil biodegradation in diverse soils. Appl. Environ. Microbiol. 72, 6316-6324.

Heller, F., Strzyszcz, Z., Magiera, T., 1998. Magnetic record of industrial pollution in forest soils of Upper Silesia, Poland. J. Geophys. Res. 103, 17767-17774.

Kapicka, A., Jordanova, N., Petrovsky, E., Ustjak, S., 2000. Magnetic stability of powerplant fly ash in different soil solutions. Phys. Chem. Earth 25, 431-436.

Kappler, A., Straub, K.L., 2005. Geomicrobiological cycling of iron. Rev. Mineral. Geochem. 59, 85-108.

Karimi, R., Ayoubi, S., Jalalian, A., Sheikh-Hosseini, A.R., Afyuni, M., 2011. Relationships between magnetic susceptibility and heavy metals in urban topsoils in the arid region of Isfahan, Central Iran. J. Appl. Geophys. 74, 1-7.

Kayode, J., Oyedeji, A.A., Olowoyo, O., 2009. Evaluation of the effect of pollution with spent lubricating oil on the physical and chemical properties of soil. Pac. J. Sci. Technol. 1 (10), 387-391.

Konhauser, K.O., Kappler, A., Roden, E.E., 2011. Iron in microbial metabolisms. Elements 7, 89-93.

Liang, M., Liang, H., Rao, Z., Hong d, Z., 2019. Characterization of polycyclic 
aromatic hydrocarbons in urban-rural integration area soil, North China: Spatial distribution, sources and potential human health risk assessment. Chemosphere. $234,875-884$.

Lindsay, W.L., 1979. Chemical Equilibrium in Soils. John Wiley \& Sons, New York.

Liu, Q.S., Chan, L.S., Yang, T., Tongjin, C., 2006. Magnetic enhancement caused by hydro-carbon migration in the Mawangimo oil field, Jianghan Basin, China. J. Pet. Sci. Eng. 53, 25-33.

Lopez Granados, F., Jurado Exposito, M., Atenciano, S., Gracia Torres, L., 2002. Spatial variability of agricultural soil parameters in southern Spania. Plant Soil 246, 97-105.

Lovley, D.R., Anderson, R.T., 2000. Influence of dissimilatory metal reduction on fate of organic and metal contaminants in the subsurface. Hydrogeol. J. 8, 7788.

Lovley, D.R., Baedecker, M.J., Lonergan, D.J., Siegel, D.J., 1989. Oxidation of aromatic contaminants coupled to microbial iron reduction. Nature 339, 297300.

Mariana, M., Toti, M., Tansae, V., Plopeanu, G., 2011. The effects of crude oil pollution on physical and chemical characteristics of soil. Agri. Sci. 43, 125129.

Martins, C.C., Mahiques, M.M., Bicego, M.C., Montone, R.C., 2007. Comparison between anthropogenic hydrocarbons and magnetic susceptibility in sediment cores from the Santos Estuary, Brazil. Mar. Pollut. Bull. 54, 240-246.

Marwick, B., 2005. Element concentrations and magnetic susceptibility of 
anthrosols: indicators of prehistoric human occupation in the inland Pilbara, Western Australia. J. Archeol. Sci. 32, 1357-1368.

McCabe, C., Sassen, R., Saffer, B., 1987. Occurrence of secondary magnetite within biodegraded oil. Geology 15, 7-10.

Meliana, U., 2017. Magnetic susceptibility analysis of soil affected by hydrocarbon in Wonocolo traditional oil field, Indonesia. Earth. Environ. Sci. $62,1745-1754$.

Morris, W.A., Versteeg, J.K., Bryant, D.W., Legzdins, A.E., McCarry, E., Marvin, H., 1995. Preliminary comparisons between mutagenicity and magnetic susceptibility of respirable airborne particulate. Atmos. Environ. 29, 34413450.

Naderizadeh, Z., Khademi, H., Ayoubi, S., 2016. Biomonitoring of atmospheric heavy metals pollution using dust deposited on date palm leaves in southwestern Iran. Atmosfera 29 (2), 141-155.

Naimi, S., Ayoubi, S., 2013. Vertical and horizontal distribution of magnetic susceptibility and metal contents in an industrial district of Central Iran. J. Appl. Geophys. 96, 55-66.

Paz Gonzalez, A., Vieira, S., Taboada Castro, M.T., 2002. The effect of cultivation on the spatial variability of selected properties of an umbric horizon. Geoderma. 97, 273-292.

Porsch, K., Rijal, L., Borch, T., Lyndsay, D., Appel, E., Kappler, A., 2014. Impact of organic carbon and iron bioavailability on the magnetic susceptibility of soils. Geochim. Cosmochim. Acta 128, 44-57.

Rijal, L., Appel, E., Petrovsky, E., Blaha, U., 2010. Change of magnetic properties 
due to fluctuations of hydrocarbon contaminated groundwater in consolidated sediments. Environ. Pollut. 158, 1756-1762.

Rijal, L., Porsch, K., Appel, E., Kappler, A., 2011. Magnetic signature of hydrocarbon-contaminated soils and sediments at the former oil field Hänigsen. Germany. Stud. Geophys. Geod. 56, 889-908.

Rodriguez Martin, J.A., Lopez Arias, M., Grau Corbi, J.M., 2006. Heavy metals contents in agricultural topsoils in the Ebro basin (Spain). Application of the multivariate geostatistical methods to study spatial variations. Environ. Pollut. $144,101-1012$.

Soil Survey Staff, 2014. Keys to Soil Taxonomy. twelfth ed. USDA Natural Resources Conservation Service, USA.

Sheldrick, B.H., 1984. Analytical methods manual. Land Resour. Res. Inst., Res. Branch. Agriculture Canada, Ottawa.

Taghipour, Ayoubi, M.S., Khadmei, H., 2011. Contribution of lithologic and anthropogenic factors to surface soil heavy metals in western Iran using multivariate geostatistical analyses. Soil Sediment Contam. 20 (8), 921-937.

Tang, J., Lu, X., Sun, Q., Zhu, W., 2012. Aging effect of petroleum hydrocarbons in soil under different attenuation conditions. Agric. Ecosyst. Environ. 149 (2012), 109-117. Uquetan, U., Osang, J., Alozie, A., Bawan, A.M., 2017. A case study of the effects of oil pollution on soil properties and growth of tree crops in cross river state. Nigeria. App. Phys. 5, 19-28.

Venkatachalapathy, R., Veerasingam, S., Basavaiah, N., Deenadayalan, K., 2011. Environmental magnetic and petroleum hydrocarbons records in sediment cores from the north east coast of Tamilnadu, Bay of Bengal, India. Marine Pollut. 
Bull. 62, 681-690.

Valaee, Morteza, Ayoubi, S., Khormali, F., Gao Lu, S., Karimzadeh, H.R., 2016. Using magnetic susceptibility to discriminate between soil moisture regimes in selected loess and loess-like soils in northern Iran. Journal of Applied Geophysics 127, 23-30.

Wild, S.R., Obbard, J.P., Munn, C.I., Berrow, M.L., Jones, K.C., 1991. The longterm persistence of polynuclear aromatic hydrocarbons (PAHs) in an agricultural soil amended with metal-contaminated sewage sludge. Sci. Total Environ. 101, $235-253$.

Xia, Z., Duan, X., Tao, S., Qiu, W., Liu, D., Wang, Y., Wei, S., Wang, B., Jiang, Q., Lu, B., Song, Y., Hu, X., 2013. Pollution level, inhalation exposure and lung cancer risk of ambient atmospheric polycyclic aromatic hydrocarbons (PAHs) in Taiyuan, China. Environ. Pollut. 173, 150-156. 
Table 1. Descriptive statistics of some chemical properties of the soil samples in the unpolluted site.

\begin{tabular}{|c|c|c|c|c|c|c|c|c|c|}
\hline Variable & Depth $(\mathrm{cm})$ & Unit & Min & Max & Mean & $\mathrm{SD}$ & Skew & Kurt & $\% \mathrm{CV}$ \\
\hline \multirow[t]{2}{*}{$\overline{\mathrm{EC}}$} & $0-10$ & $\mathrm{dS} \mathrm{m}^{-1}$ & 0.30 & 11 & 2.4 & 3.04 & 2.3 & 4.4 & 126 \\
\hline & $10-30$ & & 0.20 & 7.2 & 1.8 & 2.23 & 1.6 & 1.4 & 123 \\
\hline \multirow[t]{2}{*}{$\mathrm{pH}$} & $0-10$ & $-\log [\mathrm{H}+]$ & 7.0 & 7.8 & 7.5 & 0.30 & -0.50 & -0.9 & 4 \\
\hline & $10-30$ & & 7.0 & 7.9 & 7.4 & 0.30 & 0.05 & -1.07 & 4.05 \\
\hline \multirow[t]{2}{*}{$\chi \mathrm{lf}$} & $0-10$ & $\times 10^{-8} \mathrm{~m}^{3} \mathrm{~kg}^{-1}$ & 22.3 & 76.3 & 42.9 & 17.1 & 0.4 & -1.0 & 39.8 \\
\hline & $10-30$ & & 20.23 & 51.3 & 32.9 & 10.5 & 0.40 & 1.3 & 31.9 \\
\hline \multirow[t]{2}{*}{ ТРH } & $0-10$ & $\mathrm{~kg} \mathrm{~kg}^{-1}$ & 0.2 & 0.6 & 0.21 & 1.9 & 1.04 & -0.07 & 90.5 \\
\hline & $10-30$ & & 0.15 & 0.3 & 0.17 & 1.2 & 0.6 & -1.0 & 85.7 \\
\hline \multirow[t]{2}{*}{$\mathrm{Fe}_{\mathrm{A}}$} & $0-10$ & $\mathrm{mg} \mathrm{kg}^{-1}$ & 6543 & 12,580 & 9000 & 1773 & 0.7 & -0.5 & 19.7 \\
\hline & $10-30$ & & 6875 & 12,123 & 9367 & 1609 & 0.20 & -1.1 & 17.2 \\
\hline \multirow[t]{2}{*}{$\mathrm{Fe}_{\mathrm{d}}$} & $0-10$ & $\mathrm{mg} \mathrm{kg}^{-1}$ & 1072 & 2445 & 1700 & 377 & 0.6 & 0.3 & 22.2 \\
\hline & $10-30$ & & 980 & 2691 & 1704 & 455 & 0.7 & 0.7 & 26.7 \\
\hline \multirow[t]{2}{*}{$\mathrm{CCE}$} & $0-10$ & $\mathrm{~kg} \mathrm{~kg}^{-1}$ & 13.4 & 92.3 & 52.8 & 26.4 & 0.06 & -1.4 & 50 \\
\hline & $10-30$ & & 12.05 & 81.2 & 47.4 & 22 & 0.03 & -1.1 & 46.4 \\
\hline
\end{tabular}

Min: Minimum; Max: Maximum; SD: Standard deviation; Skew: Skewness; Kurt: Kurtosis; CV: Coefficient of variation; EC: Electrical conductivity; $\chi$ lf: Magnetic susceptibility at low frequency; TPH: Total petroleum hydrocarbons; Fe $\mathrm{A}$ : Aqua regial extractable Fe, Fed: CBD extracted Fe; CCE: Calcium carbonate equivalent. 
Table 2. Descriptive statistics of some chemical properties of the soil samples in the polluted site.

\begin{tabular}{|c|c|c|c|c|c|c|c|c|c|}
\hline Variable & Depth $(\mathrm{cm})$ & Unit & Min & Max & Mean & SD & Skew & Kurt & $\% \mathrm{CV}$ \\
\hline \multirow[t]{2}{*}{$\overline{\mathrm{EC}}$} & $0-10$ & $\mathrm{dS} \mathrm{m}^{-1}$ & 0.30 & 11.2 & 2.7 & 2.4 & 1.6 & 3.2 & 88.8 \\
\hline & $10-30$ & & 0.20 & 11 & 2.8 & 2.8 & 1.6 & 1.8 & 100 \\
\hline \multirow[t]{2}{*}{$\mathrm{pH}$} & $0-10$ & $-\mathrm{Log}[\mathrm{H}+]$ & 7.0 & 7.9 & 7.3 & 0.27 & 0.6 & 0.08 & 3.7 \\
\hline & $10-30$ & & 7.0 & 7.95 & 7.30 & 0.30 & 0.4 & -0.3 & 4.1 \\
\hline \multirow[t]{2}{*}{$\chi \mathrm{lf}$} & $0-10$ & $\times 10^{-8} \mathrm{~m}^{3} \mathrm{~kg}^{-1}$ & 18.8 & 1089 & 195.4 & 184.5 & 3.2 & 14.2 & 94.4 \\
\hline & $10-30$ & & 40.5 & 1045 & 202.4 & 186.4 & 2.7 & 10 & 92.1 \\
\hline \multirow[t]{2}{*}{ ТРH } & $0-10$ & $\mathrm{~kg} \mathrm{~kg}^{-1}$ & 0.1 & 35.8 & 6.9 & 5.4 & 4.1 & 22 & 78.2 \\
\hline & $10-30$ & & 3.1 & 31.2 & 7.26 & 4.8 & 3.5 & 16 & 66.1 \\
\hline \multirow[t]{2}{*}{$\mathrm{Fe}_{\mathrm{A}}$} & $0-10$ & $\mathrm{mg} \mathrm{kg}^{-1}$ & 5805 & 49,110 & 16,118 & 8607 & 1.6 & 4.3 & 53.4 \\
\hline & $10-30$ & & 6921 & 48,994 & 15,340 & 8872 & 2.1 & 5.3 & 57.8 \\
\hline \multirow[t]{2}{*}{$\mathrm{Fe}_{\mathrm{d}}$} & $0-10$ & $\mathrm{mg} \mathrm{kg}^{-1}$ & 770 & 4230 & 2301 & 728 & 0.6 & 0.6 & 31.6 \\
\hline & $10-30$ & & 1230 & 4196 & 2283 & 730 & 1.2 & 1.8 & 37.4 \\
\hline \multirow[t]{2}{*}{$\mathrm{CCE}$} & $0-10$ & $\mathrm{~kg} \mathrm{~kg}^{-1}$ & 14.5 & 85 & 43.3 & 15.8 & 0.2 & 0.7 & 36.5 \\
\hline & $10-30$ & & 12.9 & 83 & 46.3 & 18.8 & 0.1 & -0.7 & 40.6 \\
\hline
\end{tabular}

Min: Minimum; Max: Maximum; SD: Standard deviation; Skew: Skewness; Kurt: Kurtosis; CV: Coefficient of variation; EC: Electrical conductivity; $\chi$ lf: Magnetic susceptibility at low frequency; TPH: Total petroleum hydrocarbons; $\mathrm{Fe}_{\mathrm{A}}$ : aqua regial extractable Fe, Fed: CBD extracted Fe; CCE: Calcium carbonate equivalent. 
Table 3. Correlation coefficients between soil properties, magnetic measures and total petroleum hydrocarbons content of the 120 soil samples.

\begin{tabular}{lllllll}
\hline Variable & CCE & $\mathrm{pH}$ & $\mathrm{EC}$ & $\mathrm{TPHs}$ & $\mathrm{Fe}_{\mathrm{d}}$ & $\mathrm{Fe}_{\mathrm{A}}$ \\
\hline$\chi^{\mathrm{lf}}$ & $-0.19^{*}$ & $-0.26^{* *}$ & $-0.33^{* *}$ & $0.88^{* *}$ & $0.71^{* *}$ & $0.83^{* *}$ \\
TPHs & 0.08 & $-0.15^{*}$ & $0.33^{* *}$ & 1 & $0.59^{* *}$ & $0.63^{* *}$
\end{tabular}

ұlf: Magnetic susceptibility at low frequency; TPH: Total petroleum hydrocarbons.

** Significant at 0.01 probability level; * Significant at $0.05 \%$ probability level. 


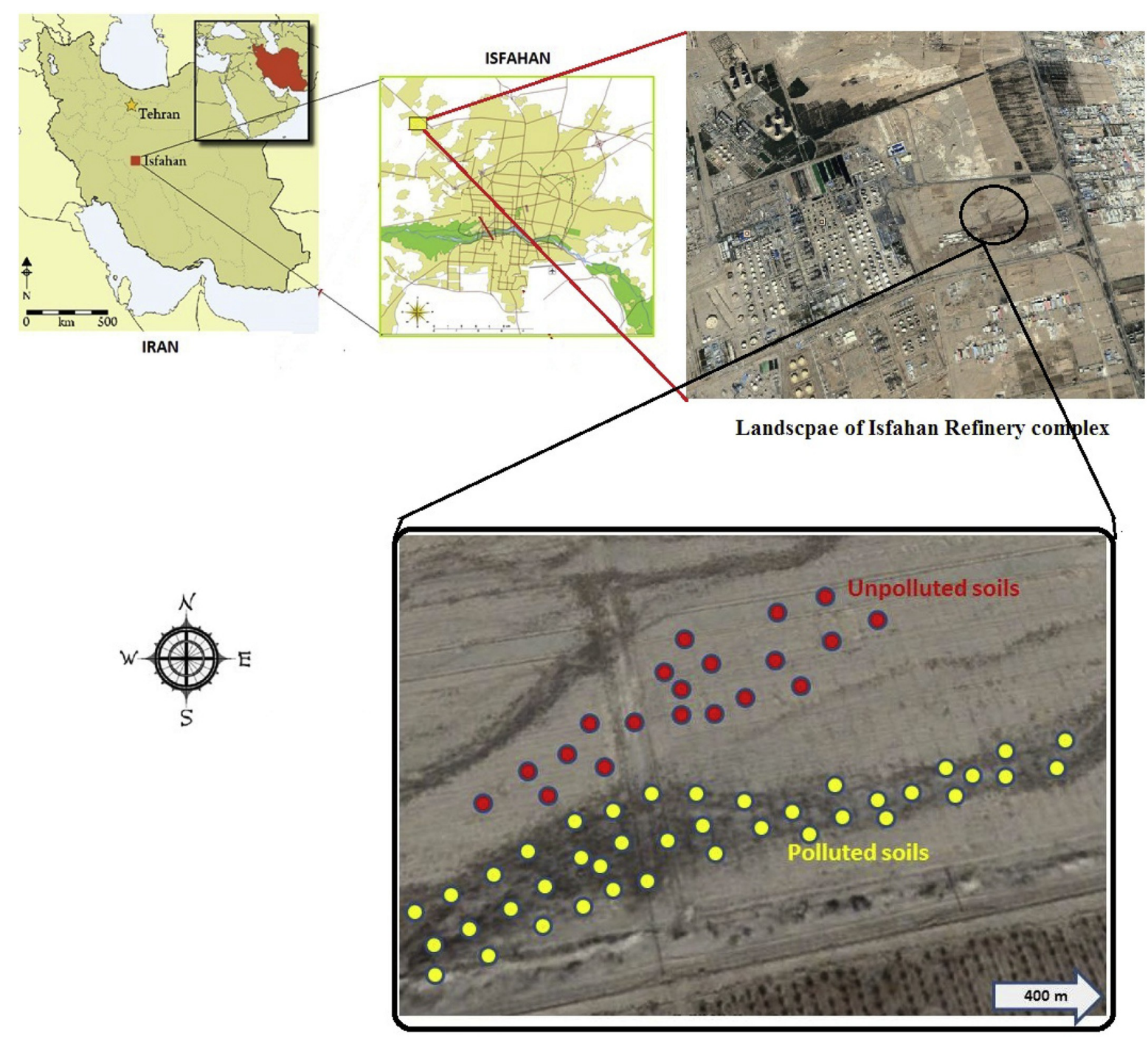

Fig. 1. Location of the study area in the petroleum refinery of Isfahan, Isfahan city, central Iran, distribution of sampling points are shown by red points (unpolluted soils) and yellow ones (polluted soils). 

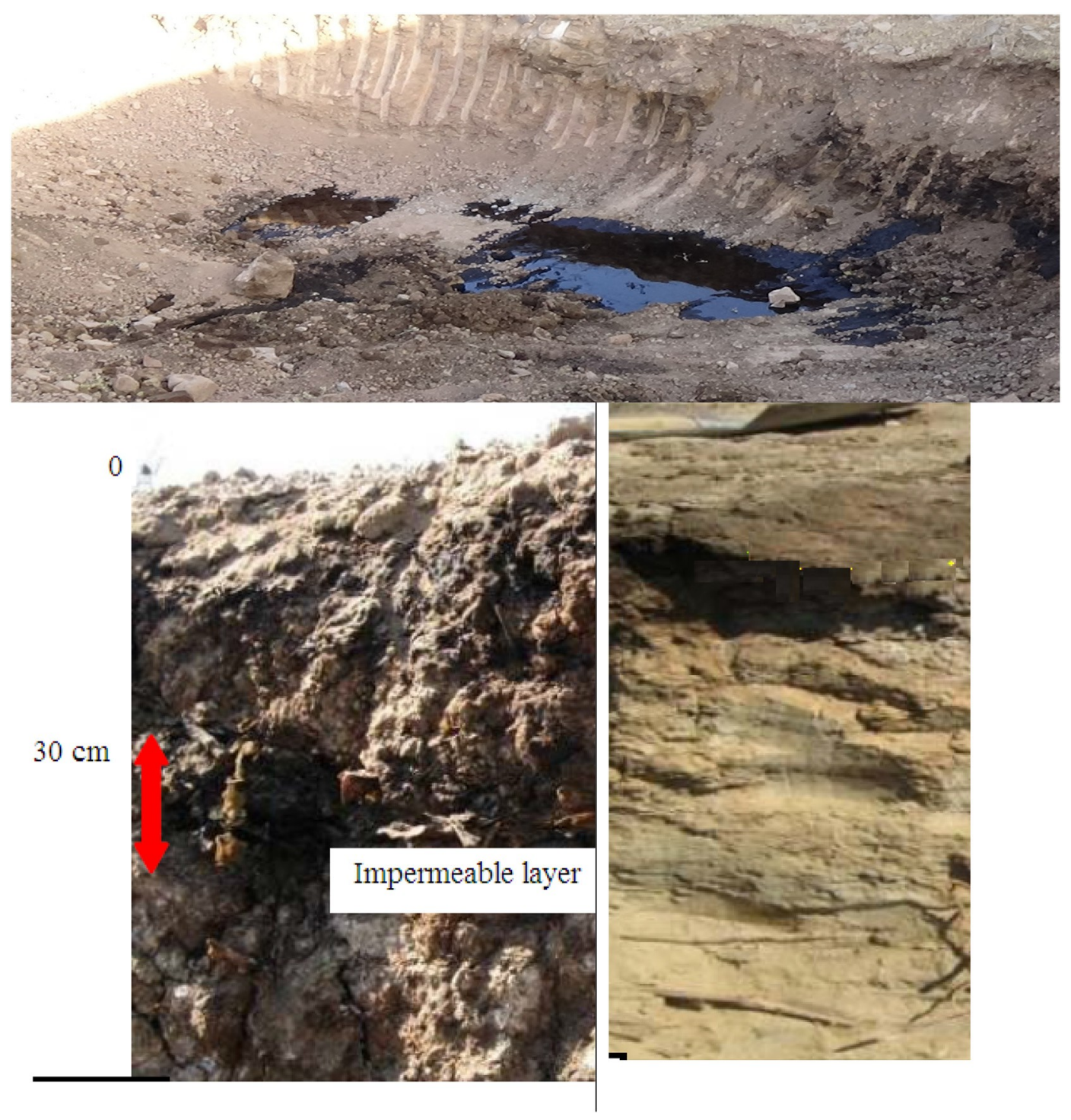

Fig. 2. Some illustrations of surface leakage of crude oil around the studied oil refinery at Isfahan city, Central Iran. 

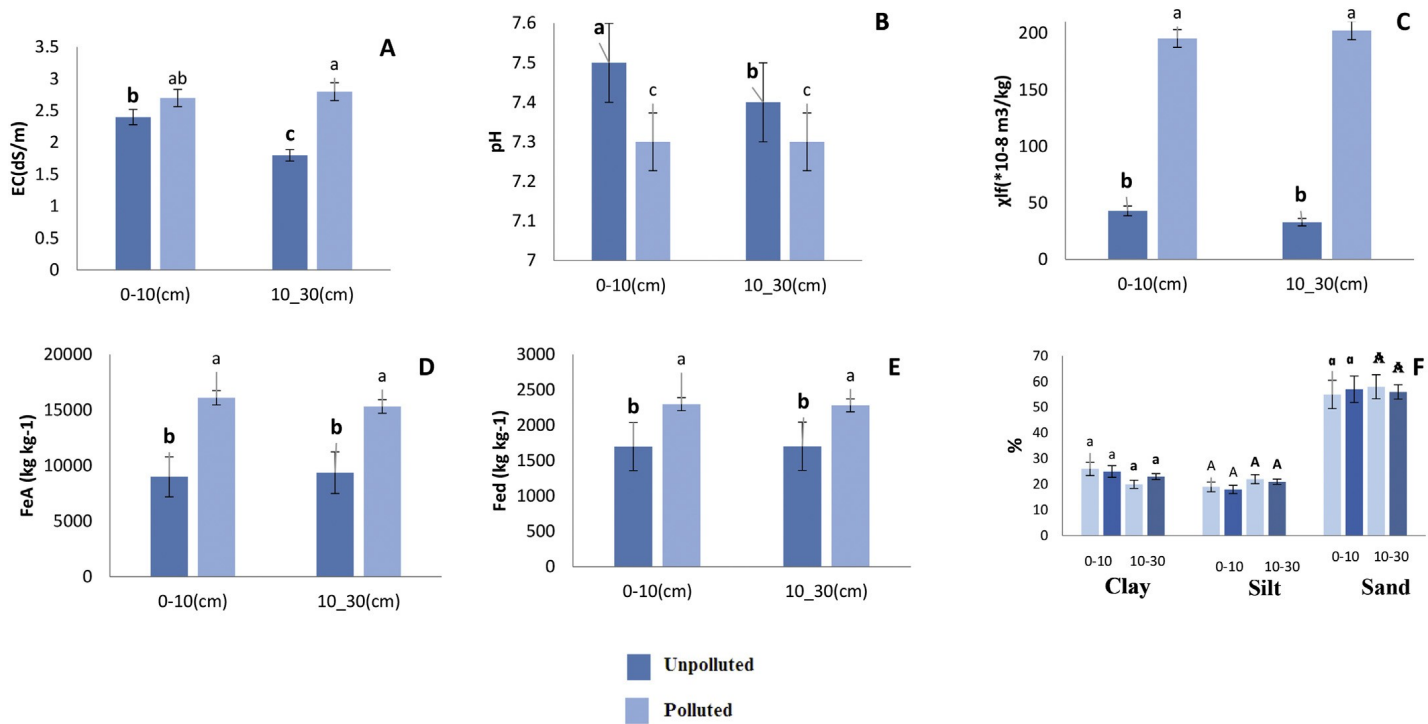

Fig. 3. Comparisons of the means of the variables of the polluted and unpolluted sites and for two depths of $0-10$ and $10-30 \mathrm{~cm}$ in the study area. A) EC, B) pH, C) Magnetic susceptibility at low frequency, Fet, D) $\left.\mathrm{Fe}_{\mathrm{A}}, \mathrm{E}\right) \mathrm{Fe}_{\mathrm{d}}$ F) clay, silt and sand distribution. 

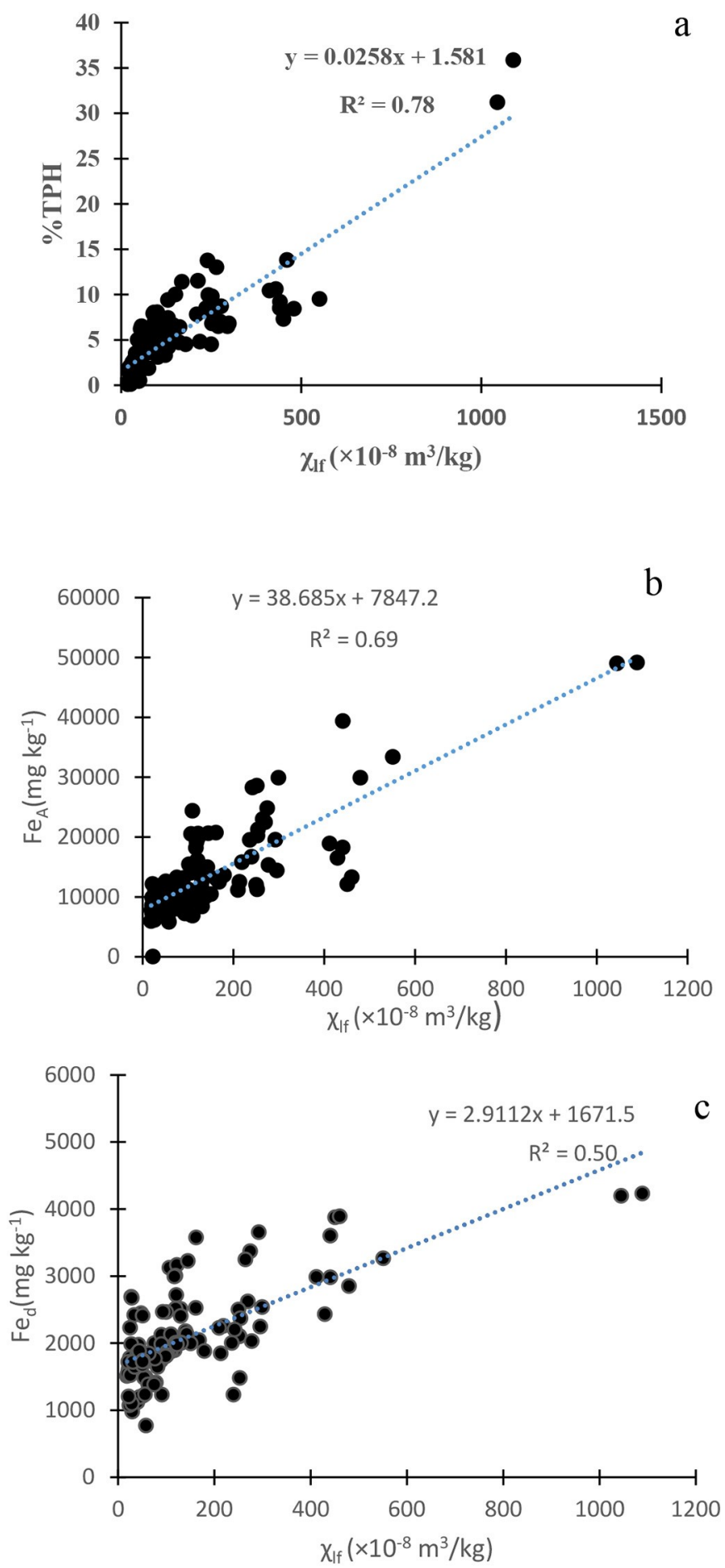

Fig. 4. Linear relationships between some studied soil properties and TPH content and magnetic susceptibility. a) $\chi$ lf vs. TPH, b) $\chi$ lf vs. Fe $\mathrm{A}$, c) $\chi$ lf versus Fed. 

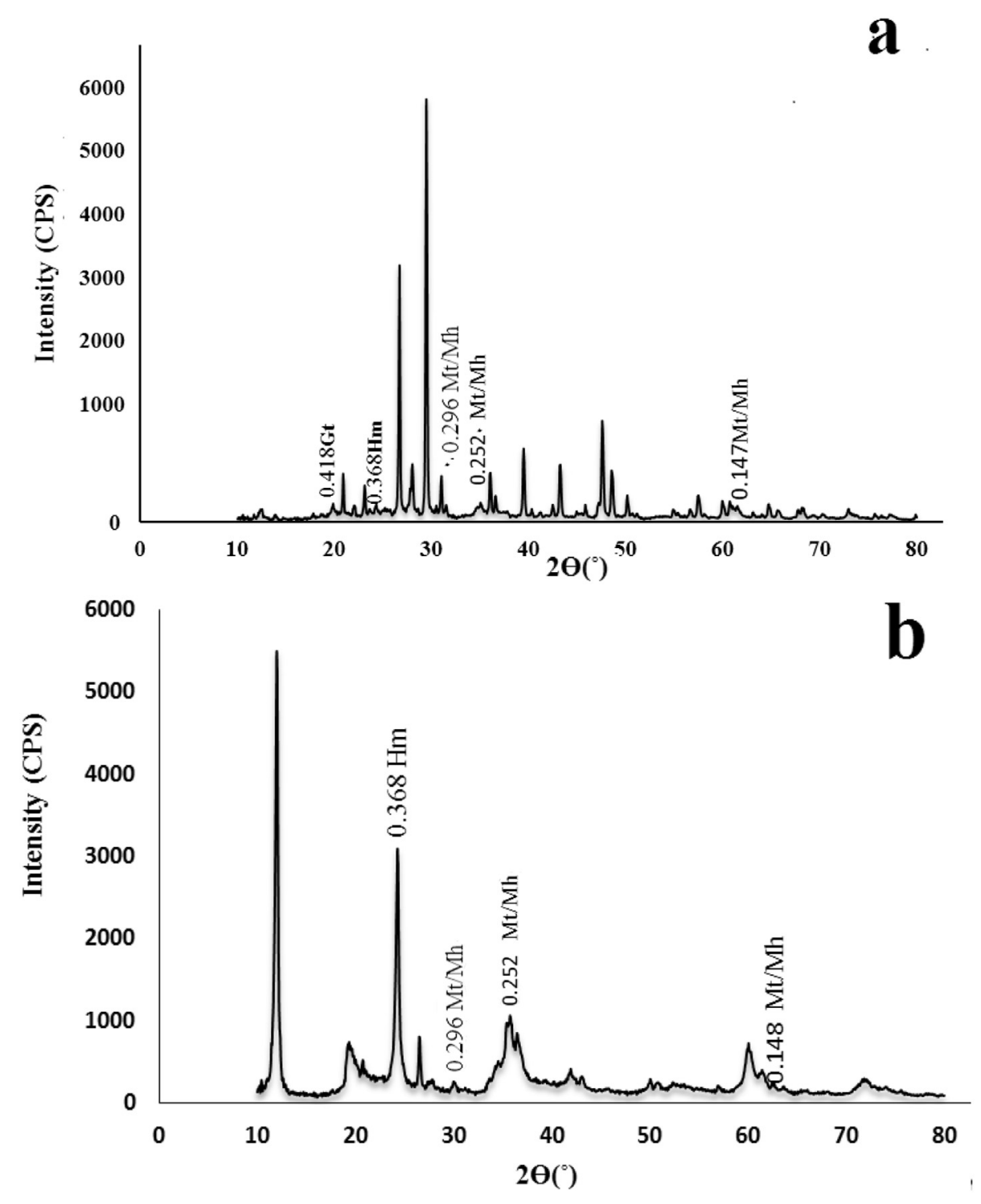

Fig. 5. X-Ray diffractograms of some studied soils for detecting iron bearing minerals.

a) unpolluted soil, b) polluted soil. Hm: Hematite, Mt.: Magnetite, Mh: Maghemite, Gt:" Goethite. 